\title{
EDITORIAL
}

\section{The making of the ERJ: behind the scenes and Editors' cut}

\author{
A.T. Dinh-Xuan* and V. Brusasco ${ }^{\#}$
}

W e began our editorship of the European Respiratory Journal (ERJ) 18 months ago, with the hope of serving the ERJ using modern communication media in order to advance respiratory medicine and its related biological and therapeutic research fields [1]. Due to this, over the last 12 months a series of changes have been introduced to reshape the ERJ and meet the expectations and demands of our readers and fellow investigators worldwide [2]. Now, at almost the mid-point of our mandate, whilst briefly looking back at the last 18 months, we want to continue to share with you information relating to the daily work procedure of the ERJ Editorial Office. In doing so, we hope to provide you with greater transparency, thereby bringing the ERJ not only closer to the eyes, but also the hearts and minds of its readership.

Quantitatively, the number of manuscripts submitted to the ERJ has risen steadily from around 1,500 per year in 2005 to more than 2,000 since 2008. We do not know whether this increase in submissions is the result, or the cause, of the increased impact factor of the ERJ $[3,4]$. However, what we do know is that the absolute number of manuscripts we have received from the day we began our editorship has already amounted to more than 3,000. Of these submitted manuscripts, $14 \%$ have received an immediate decision directly from the Chief Editors (without consulting the other members of the Editorial Board). Indeed, we have immediately accepted, mostly invited editorials and correspondences, or rejected manuscripts where the topics did not obviously fit with those of the ERJ. However, for the majority of manuscripts submitted to the ERJ, i.e. the remaining $86 \%$, a decision has been made involving at least two or three members of the Editorial Board, including the Chief Editors, and the participation of external reviewers who helped us by providing their invaluable expertise [5]. To avoid unnecessary solicitations of our expert reviewers, we decided to submit every manuscript to a meticulous and immediate evaluation, made by members of the Editorial Board, with the key question being whether the manuscript should be immediately rejected for publication, or whether it should be sent for external review. By returning 30\% of submitted manuscripts to the authors within the first 3 days following submission, we have deliberately chosen the policy

\footnotetext{
*Dept of Cardiopulmonary Medicine, Cochin Hospital, University Paris Descartes, Paris, France. ${ }^{*}$ Dept of Internal Medicine, Medical School, University of Genoa, Genoa, Italy.

of reducing the waiting time for unsuccessful authors and, at the same time, reduced the workload of our, often over solicited, expert reviewers. In order to maximally reduce the risk of overlooking important messages we take great care to discuss all rejection decisions with the Associate Editor(s) in charge of the manuscript, in addition to justifying our collective decision with detailed comments written by the Associate Editor(s) and approved by several members of the Editorial Board. Authors have, on some occasions, made an appeal regarding the decision that has been made, specifically asking that their manuscript be evaluated by external reviewers and clearly stating their preference to wait a few more weeks for the final verdict accompanied by external reviewers' comments. We always comply with the authors' requests but the final outcomes remain unchanged, with confirmatory recommendations from the reviewers (to reject the paper) in all cases to date.

Obviously the ERJ has now become a journal where publishing original work has become competitive, as the acceptance ratio has dropped to around $15 \%$ of submitted manuscripts. Due to this increased selectivity, one question naturally arises in relation to manuscripts submitted to the ERJ by members of the Editorial Board is the guarantee that these papers are handled in such a manner as to avoid insider bias [6]. To address this important issue we have relied on the selfcensorship of all current Editorial Board members, Associate Editors and Chief Editors. More importantly, extra care has been made to ensure that only manuscripts with unquestionable scientific quality, as underlined by external reviewers' comments, can pass through the stringent ERJ selection criteria. As a result, we have identified 16 original manuscripts co-authored by members of the current Editorial Board among the 2,050 manuscripts submitted to the ERJ during 2009. From this very low number of manuscripts $(0.8 \%$ of the total number of submitted manuscripts), only six made it through the selection process. One may argue that the success rate of our editors, i.e. $37.5 \%$, is still higher than the average rate of acceptance of the ERJ. To this statement we would argue that our editors have most probably already exercised self-censorship by submitting only their most important studies to the ERJ last year, still with a $62.5 \%$ rejection rate. In support of this argument we have identified a significant number of manuscripts co-authored by our editors among the highest citing manuscripts published by the ERJ during the last 2 yrs [7-12]. So, where do the Chief Editors stand in this setting, and how should our manuscripts be handled by our fellow editors? The initial, and probably easiest, solution would be for the Chief 
Editors to restrain from submitting any original manuscripts during our mandate. Whilst this proposal may help to lift some of the possible interrogations related to potential conflict of interests pertaining to manuscripts published by the ERJ Chief Editors, this would also imply that this rule should be applied to all members of the current ERJ Editorial Board in order to make it fully consistent with the proposed editorial policy. Knowing the expertise and high scientific standard of our editors, the risk would be to deprive the ERJ from the possibility of publishing some of the most significant papers in respiratory fields, and to consequently divert the very same papers to other medical journals. Such a decision would not stand and we have, therefore, decided not to implement the above policy during the present mandate. However, a consensus was produced during the Editorial Board meeting and the subsequent Publications Committee Meeting at the 2009 European Respiratory Society (ERS) Annual Congress in Vienna, which clearly states the rules for manuscripts submitted by the ERJ Chief Editors. First, all manuscripts submitted to the ERJ should be concealed from the submitting authors with no exception, i.e. including all ERJ editors. Secondly, the Associate Editors handling manuscripts submitted to the ERJ by the Chief Editors will make their decision independently of the submitting authors. Thirdly, in case of contradictory recommendations from external reviewers, the Associate Editor in charge of the manuscript may seek advice from previous ERJ Chief Editors who are current members of the ERJ International Advisory Board. Finally, in the situation of the manuscript being rejected, the Chief Editors should restrain from making any appeal to reverse the Associate Editor's decision. We hope that with these clearly defined rules we have made the process of all submission procedures to the $E R J$ as transparent as possible, and avoid the occurrence of conflicts of interest in the editorial process, especially when related to manuscripts written by members of the Editorial Board.

Editing the ERJ is a fascinating enterprise that can only succeed if the resulting work stems from collaborative efforts from all members of the ERJ and its readership [1]. During the last 18 months we have been fortunate enough to collaborate with many supportive colleagues, two of whom, Prof. A. Bush and Prof. O. Eickelberg, will be leaving the Editorial Board starting on July 1, 2010 to take over new tasks and scientific responsibilities. Prof. Bush will become the next Co-Chief Editor of Thorax and Prof. Eickelberg has been elected as the new ERS Conferences and Seminars Director. Whilst wishing them both all our best, we would like also to welcome Prof. P. Hiemstra from the Netherlands and Prof. P. Sly from Australia who have graciously accepted to join the ERJ Editorial Board. A lot of work still needs to be done but we stand firm and ready. We stay confident too, knowing that the work will be done together, as it has been for the last 18 months.

\section{STATEMENT OF INTEREST}

Statements of interest for both authors can be found at www.erj. ersjournals.com $/ \mathrm{misc} /$ statements.dtl

\section{REFERENCES}

1 Dinh-Xuan AT, Brusasco V. The ERJ in its 21st year of age: a smooth transition for an everlasting evolution. Eur Respir J 2009; 33: $1-2$.

2 Dinh-Xuan AT, Brusasco V. Refining the changes. Or, how to modify the shape, not the spirit. Eur Respir J 2009; 34: 1 .

3 Rabe KF, Sterk PJ. Five good reasons to read (and cite) the ERJ. Eur Respir J 2008; 31: 1-2.

4 Rabe KF, Sterk PJ. Your 10,000 manuscripts. Eur Respir J 2008; 32: 1425.

5 European Respiratory Journal List of Reviewers. http://erj. ersjournals.com/misc/reviewers.dtl

6 Curfman GD, Drazen JM. Too close to call. N Engl J Med 2001; 345: 832.

7 Fabbri LM, Luppi F, Beghé B, et al. Complex chronic comorbidities of COPD. Eur Respir J 2008; 31: 204-212.

8 Dupuis J, Hoeper MM. Endothelin receptor antagonists in pulmonary arterial hypertension. Eur Respir J 2008; 31: 407-415.

9 Migliori GB, Lange C, Centis R, et al. Resistance to second-line injectables and treatment outcomes in multidrug-resistant and extensively drug-resistant tuberculosis cases. Eur Respir J 2008; 31: 1155-1159.

10 Chaouat A, Naeije R, Weitzenblum E. Pulmonary hypertension in COPD. Eur Respir J 2008; 32: 1371-1385.

11 Montani D, Price LC, Dorfmuller P, et al. Pulmonary venoocclusive disease. Eur Respir J 2009; 33: 189-200.

12 Cottin V, Fabien N, Khouatra C, et al. Anti-elastin autoantibodies are not present in combined pulmonary fibrosis and emphysema. Eur Respir J 2009; 33: 219-221. 